\title{
ACUTE PESTICIDE INTOXICATIONS IN VARNA REGION, BULGARIA, DURING THE PERIOD 1991-2005
}

\author{
Marinov P., Iovcheva M. \\ Department of Toxicology, Naval Hospital - Varna \\ Reviewed by: Assoc. Prof. D. Radoinova
}

\section{SUMMARY}

The acute pesticide intoxications have a small relative part but quite often cause severe poisonings and death. A retrospective analysis of the epidemiology of acute pesticide intoxications /API/ in Varna region during the period 1991-2005 has been done. It was established that 384 patients with pesticide poisoning have been admitted for treatment which is $\mathbf{3 . 0 6} \%$ from all the patients with acute intoxications. API were more frequent in men. The proportion between male and female patients with API was 1.69:1. The prevailing part of the intoxicated was young and active people but a tendency was observed toward increasing of the average age. The main cause of API was suicidal attempt - 264 cases $/ 64.06 \%$ / followed by household poisonings $-34.38 \%$ and single professional intoxications $\mathbf{- 1 . 5 6 \%}$. The oral ingestion dominated as way of entry in the organism $\mathbf{7 7 . 6 1 \%}$. Respiratory and/ or percutaneous intoxications were significantly less frequent. $53 \%$ of all the pesticide poisonings were caused by organophosphate pesticides /OPP/. The lethality from pesticide poisonings is $11.72 \%$ and is significantly higher than the total lethality from acute exogenous intoxications in Varna region $-1.3 \%$.

Key words: pesticides, acute intoxications

\section{INTRODUCTION}

The pesticides are a big group of chemical compounds with various structure and toxicity (9) used for struggle with plant pests and diseases. A contact with pesticides can cause acute and chronic intoxications and long term disorders $(7,17)$. The acute intoxications have a different severity -from local irritative disorders to grave systemic disorders and death (16). The acute pesticide poisonings are a well known cause of morbidity and lethality all over the world, especially in the developing countries $(7,18,22,23)$. In some countries more than a half of the poisonings are due to pesticides (21). During the last years the main reasons for API were suicidal attempts $(6,10,14,15,21,26)$, which determine a high lethality especially from poisonings with dipyridines and organophosphates (2 $4,13,14,17,19,25,26)$. The major part of the intoxications involve people in active age $(15,17,19,26)$. At the same time significant differences in API have been observed in different countries and regions of the world.

In this relation we have put ourselves a task to study the epidemiology of those pesticide intoxications in Varna region, which succeed to reach hospital treatment, to establish the frequency of the acute pesticide exogenous intoxications, the relative share of the different pesticide groups, the distribution according to age, sex, reasons for intoxication and entry.

\section{MATERIAL AND METHODS}

The case files of 384 patients with acute pesticide poisonings treated at the Department of Toxicology - Naval Hospital-Varna have been analyzed. The investigation is retrospective and covers the period 1991-2005. Lethal cases of patients who had died at home were not included in this study. It includes 7 basic indexes: frequency, distribution according to the age, sex, reasons for intoxications, entry, type of the pesticide and lethality. A chromatic mass-spectrometric method has been used in order to confirm the intoxication and to make identification of the pesticide (1).

\section{RESULTS AND DISCUSSION}

During the period 1991- 2005 a total number of 12565 patients with acute intoxications at the age over 14 years were treated at the department of Toxicology, Naval Hospital-Varna. In 384 cases acute pesticide intoxication was the cause of the hospitalization. The frequency of API was $3.06 \%$ from all the acute intoxications that had led to hospitalization. This frequency coincides with the reported frequency in England and Wells (25). The relative share of the pesticide intoxications is greater in countries with widespread pesticide use, mainly developing countries and countries where pesticides from high toxic groups are used. During the last 20 years in our country the frequency of the 
pesticide poisonings is reduced as a consequence of the forbiddance of a lot of highly toxic preparations /Parathion, Intrathion, DDT, Lindane, Paraquat, etc./. The tendency is to use highly effective towards the pests pesticides which at the same time are less toxic to people.

The acute pesticide intoxications in men were 241 $/ 62.76 \%$ / and in women $-143 / 37.24 \% /$.

The proportion between men with API to women with API was 1.69:1. The higher frequency of pesticide poisonings in men can be explained by the fact that usually men deal with pesticides and therefore have easier access to them.

The age of the observed patients was between 14 and 92 years. The age distribution is presented on table 1 .

Table 1. Age distribution of patients with API

\begin{tabular}{||l|c|c||}
\hline Age / years/ & Number of patients & Percentage \\
\hline $14-24$ & 61 & $15.89 \%$ \\
\hline $25-44$ & 96 & $25.0 \%$ \\
\hline $45-60$ & 122 & $31.77 \%$ \\
\hline Over 60 & 105 & $27.34 \%$ \\
\hline Total & 384 & $100 \%$ \\
\hline \hline
\end{tabular}

The prevailing part of the intoxications was of young people and people in active age. This coincides with the data about API in the specialized literature $(15,17,19,26)$. At the same time in our country a tendency was outlined at the end of the last century to an increase of the average age of the intoxicated with pesticides. The poisonings in elder patients suppose more grave clinical picture as a result of the existing serious co morbidity with age progression which undoubtedly influences the clinical course and outcome of the intoxication. The "shift" of the age borders of patients with API is a consequence of the deep changes of cultivating and managing of the land in the new conditions of market economy which led to different pattern of pesticide use. Their use in private farms grew bigger. Mainly elder farmers work with them there.

The main reason for API were suicidal attempts - 246 cases $/ 64.06 \% /$, followed by household -132 cases $/ 34.38 \%$ / and professional intoxications - 6 cases $/ 1.56 \% /$.

Table 2. Reasons for API

\begin{tabular}{||l|c|c||}
\hline \hline $\begin{array}{l}\text { Reason for } \\
\text { intoxication }\end{array}$ & Number of cases & Percentage \\
\hline Suicidal attempts & 246 & $77.61 \%$ \\
\hline $\begin{array}{l}\text { Household } \\
\text { poisonings }\end{array}$ & 132 & $34.38 \%$ \\
$\begin{array}{l}\text { Professional } \\
\text { poisonings }\end{array}$ & 6 & $1.56 \%$ \\
\hline Total & 384 & $100 \%$ \\
\hline \hline
\end{tabular}

We establish a very low relative share of professional pesticide intoxications which were leading in the near past. Today the suicidal attempts have the highest relative part, followed by household intoxications. These results are similar to the results of other authors $(6,10,14,15,19,26)$. The high frequency of the suicidal pesticide poisonings supposes that severe forms of API will become more frequent as the ingested pesticide dose in cases of suicidal attempts is much greater than that in household and especially in professional intoxication.

The oral entry of pesticides in the organism dominates 298 cases $-77.61 \%$ /Table $3 /$.

Table 3. Distribution of the patients with API according to the entry.

\begin{tabular}{||l|c|c||}
\hline $\begin{array}{l}\text { Entry / route of } \\
\text { entrance/ }\end{array}$ & Number of cases & Percentage \\
\hline Oral ingestion & 298 & $77.61 \%$ \\
\hline Inhalation & 72 & $18.75 \%$ \\
\hline Per cutaneous & 9 & $2.34 \%$ \\
\hline Combined & 5 & $1.30 \%$ \\
\hline Total & 384 & $100 \%$ \\
\hline
\end{tabular}

On the second place but with considerably lower frequency is the inhalation route of entrance- $18.72 \%$ followed by cutaneous and combined routes of entrance. The most frequent entry is through the digestive system because the prevailing part of the poisonings is either suicidal or accidental, when the pesticides are kept improperly. The professional intoxications which had the major part in the near past now are rare. As in professional intoxications the pesticides enter the organism by inhalation and/or through the skin this explains why respiratory pesticide intoxications are rarer and dermal and combined intoxications are very rare.

We have grouped the pesticides that have caused acute intoxications during the observed period in 6 groups. Table 4 presents the relative part of these groups.

Table 4. Distribution of API according to the type of the intoxicating pesticide.

\begin{tabular}{||l|c|c||}
\hline \hline Pesticides & Number of cases & Percentage \\
\hline Organophosphates & 207 & $53.9 \%$ \\
\hline $\begin{array}{l}\text { Synthetic } \\
\text { pyrethroides }\end{array}$ & 86 & $22.4 \%$ \\
\hline Carbamates & 4 & $1.04 \%$ \\
\hline Copper sulphate & 24 & $6.25 \%$ \\
\hline Organic rodenticides & 38 & $9.9 \%$ \\
\hline Zinc phosphide & 25 & $6.51 \%$ \\
\hline Total & 384 & $100 \%$ \\
\hline \hline
\end{tabular}


The acute intoxications are caused most often by organophophate pesticides - in 207 cases /53.9\%/. These are the most frequently used pesticides in our country. Similar data is reported from other countries $(3,5,6$, $14,17,18,23)$. This high relative share in our study is due to the widespread use of OP pesticides in the region, a lot of which are significantly toxic to man as well as to the strongly restricted use of other highly toxic pesticides like dipyridiles, chlororganic pesticides and other groups. Pyrethroid pesticides are on the second place according to the frequency of API - 86 cases $/ 22.4 \% /$. Their use is increasing constantly because of their high effectiveness against the pests and lower toxicity to people. Pyrethroid intoxications are generally lighter and milder. Organic rodenticide poisonings are also lighter. In our study their frequency is on the third place - 38 cases $19.9 \% /$. In some reports the organic rodenticide intoxications take the first place among other pesticide intoxications and deserve special attention $(12,25)$. The poisonings with zinc phosphide and copper sulphate are not quite frequent but these compounds are among the pesticides that lead to lethal intoxication.

Lethal outcome was registered in 45 patients with API from all 384 cases of API. The lethality from pesticide intoxication was $11.72 \%$. This lethality is significantly higher than the total lethality from acute exogenous intoxications in Varna region during the described period $-1.3 \%$. The reported death rate from pesticide poisonings coincides or is similar to the reported lethality in other investigations $(3,6,17,25,26)$.At the same time much greater lethality was shown in some reports but they refer to some concrete highly toxic pesticides as paraquate - up to $70 \%$ (14) or organophosphates- up to $50 \%$ (13). Lethal cases from pesticide intoxication have the major relative share of all the causes of death from acute exogenous intoxications. They are the cause of death for $27.61 \%$ of the total lethality from acute intoxications. The results are similar to those reported about a neighbor country - Turkey (15).

\section{CONCLUSION}

The frequency of the acute pesticide intoxications in Varna region during the period $1991-2005$ was $3.06 \%$. API were more frequent in male patients. The proportion between male and female patients was 1.69:1. The prevailing part of the intoxications was of patients in young and active age. Oral ingestion dominates as a route of entry of the pesticides into the organism. The main reason about the poisonings was suicidal attempt $/ 64.06 \% /$. More than a half of all the pesticide intoxications were caused by organophosphate pesticides. Lethality from pesticide intoxications was $11.07 \%$ and was nine times higher than the total lethality from acute exogenous intoxications in the region during the same period.

\section{REFERENCES}

1. Събева Ю., В.Славова, С.Маркова. Хромато-масспектрометричен метод за химикотоксикологична диагностика на остри отравяния с пестициди. Годишен сборник ИМАБ, т.5, 1, 1999, 55-56.

2. Batra AK., Keoliya AN., Jadhav GU. Poisoning: an unnatural cause of morbidity and mortality in rural India. J Assoc Physicians India. 2003; 51: 955-9.

3. Chen SY., Wang HF., Yin Y. The reporting system of acute pesticides poisoning and general situation of pesticides poisoning in China. Zhonghua Lao Dong Wei Sheng Zhi Ye Bing Za Zhi. 2005; 23(5): 336-9.

4. Daisley H., Simmons V. Forensic analysis of acute fatal poisonings in the sothern districts of Trinidat. Vet Hum Toxicol. 1999; 41(1): 23-5.

5. Dharmani C., Jaga K. Epidemiology of acute organophosphate poisoning in hospital emergency room patients. Rev Environ Health. 2005; 20 (3): 215-32.

6. Duran-Nah JJ., Colli-Quintal J. Acute pesticide poisoning. Salud Publica Mex. 2000; 42(1): 53-5.

7. Ferrer A. Pesticide poisoning. An Sist Sanit Navar. 2003; 26(1): 155-71.

8. Kamel F., Engel LS., Gladen BC. et al. Neurologic symptoms in licensed pesticide applicators Agricultur Health Study. Hum Exp Toxicol. 2007; 26(3): 243-50.

9. Kotwica M., Czerczak S., Rogaczewska A. The pattern of acute poisonings with pesticides in Poland during the periods 1989-1990 and 1994-1995. Przegl Lek. 1997; 54(10): 689-92.

10. London L., Flisher AJ., Wesseling C. Suicide and exposure to organophosphate insecticides: cause and effect? Am J Int Med. 2005; 47(4): 308-21.

11. Macan J., Varnai VM., Turk R. Health effects of pyrethrins and pyrethroids. Arh Hig Rada Toksicol. 2006; 57(2): 237-43.

12. Mahieu P., Lauwerys R., Dive A. et al. Poisoning by some insecticides, herbecides and fungicides. Acta Clin Belg Suppl. 1990; 13: 75-85.

13. Munidasa UA., Gawarammana IB., Kularante SA. et al. Survival pattern in patients with acute organophosphate poisoning receiving intensive care. J Toxicol Clin Toxicol. 2004; 42(4): 343-7.

14. Nagami H., Nishigaki Y., Matsushima S et al. Hospital-based survey of pesticide poisoning in Japan, 1998-2002. Int Occup Environ Health. 2005; 11(2): 180-4.

15. Nesime Y., Lokman B., Akif IM. et al. Acute pesticide poisoning related deaths in Turkey. Vet Hum Toxicol. 2004; 46(6): 342-4.

16. O'Malley M. Clinical evaluation of pesticide exposure and poisoning. Lancet. 1997; 349(9059): 1161-6.

17. Recena MC., Pires DX., Caidas ED. Acute poisoning with pesticides in the state Mato Grosso do Sul, Brasil. Sci Total Environ. 2006; 357(1-3): 88-95.

18. Rusyniak DE., Nanagas KA. Organophosphate poisoning. Semin Neurol. 2004; 24(2): 197-204. 
19. Seydaoglu G., Satar S., Alparslan N. Frequency and mortality risk factors of acute adult poisoning in Adana, Turkey, 1997-2002. Mt Sinai J Med. 2005;72(6):393-401.

20. Simpson WM., Schuman SH. Recognition and management of acute pesticide poisoning. Am Fam Physician. 2002; 65(8): 1599-604.

21. Srivastava A., Peshin S., Kaleekal T. et al. An epidemiological study of poisoning cases reported to the National Poisons Information Centre, All India Institute of Medical Sciences, New Delhi. Hum Exp Toxicol. 2005; 24(6): 279-285.

22. Tagwireyi D., Ball DE., Nhachi CF. Toxicoepidemiology in Zimbabwe: pesticide poison- ing admissions to major hospitals. Clin Toxicol. 2006; 44(1): 59-66.

23. Tsai JR., Sheu CC., Cheng MH. et al. Organophosphate poisoning: 10 years of experience in Taiwan. Kaohsiung J Med Sci. 2007; 23(3): 112-9.

24. Tsatsakis AM., Tsakalof AK., Siatitsas Y. et al. Acute poisoning with carbamate pesticides: the Cretan experience. Sci Justice. 1996; 36(1): 35-9.

25. Vale TJ., Meredith TJ., Buckley BM. Acute pesticide poisoning in England and Wales. Health Trends. 1987; 19(1): 5-7.

26. Van der Hoek W., Konradsen F. Risk factors for acute pesticide poisoning in Sri Lanka. Trop Med Int Health. 2005; 10(6): 589-96. 